\title{
Pregnancy Confirmed Indicator
}

National Cancer Institute

\section{Source}

National Cancer Institute. Pregnancy Confirmed Indicator. NCI Thesaurus. Code

C122192.

Specifies whether the subject's pregnancy has been confirmed. 